\title{
Modeling and validating tritium transfer in a grassland ecosystem in response to $3 \mathrm{H}$ release
}

\author{
S. Le Dizès ${ }^{1}$, H. Renard ${ }^{1}$, F. Vermorel ${ }^{2}$, D. Maro ${ }^{1}$, C. Aulagnier ${ }^{2}$, \\ M. Rozet ${ }^{1}$, D. Hébert ${ }^{1} \&$ L. Solier ${ }^{1}$ \\ ${ }^{1}$ Institute for Radioprotection and Nuclear Safety, France \\ ${ }^{2}$ Electricité de France, France
}

\begin{abstract}
In this paper a radioecological model for tritium transfer in a grassland ecosystem developed on an hourly time-step basis is proposed and compared with the first data set obtained in the vicinity of the AREVA NC reprocessing plant of La Hague (France).

Keywords: tritium transfers, process-oriented model, data acquisition and processing, grassland ecosystem.
\end{abstract}

\section{Introduction}

Tritium $\left({ }^{3} \mathrm{H}\right)$ is a major radionuclide released by the French nuclear facilities during normal operation, whether in gaseous or liquid waste discharges. Mainly released as tritiated water vapor (HTO) in the atmosphere, tritium can be readily integrated into terrestrial ecosystems through plant photosynthesis, and then follows the cycle of stable hydrogen (and hence water) throughout the food chain. To assess ${ }^{3} \mathrm{H}$ transfer into the environment for the calculation of human dose, it is important to develop models that are not only operational - i.e. based on a limited number of easily accessible parameters - but also tested against extensive sets of field measurements. In addition, among the many existing models in the literature, to our knowledge, there are very few models that predict ${ }^{3} \mathrm{H}$ transfer in terrestrial environment in response to discrete atmospheric releases from a nuclear facility.

The TOCATTA model developed at the Institute for Radioprotection and Nuclear Safety (IRSN) aims at estimating tritium (and carbon-14, ${ }^{14} \mathrm{C}$ ) transfer in terrestrial ecosystems, in response to continuous or discrete atmospheric releases, or combinations thereof. The model was previously tested for ${ }^{14} \mathrm{C}$ by comparison 
with a set of field measurements - covering a two-year period - in the framework of the Validation of TOCATTA (VATO) study [1]. The main conclusion drawn from these comparisons has highlighted the need to develop an hourly time step model of ${ }^{14} \mathrm{C}$ transfer based more thoroughly on knowledge arising from plant physiology, soil science and meteorology [1]. Thus, by increasing the temporal resolution of the model, a new version recently developed, called TOCATTA- $\chi$, can simulate the impact of intermittent ${ }^{14} \mathrm{C}$ releases occurring either the day or night.

Regarding tritium, a previous study [2] has thrown light upon the efforts needed to produce more conclusive future modelling and experimental studies on ${ }^{3} \mathrm{H}$ transfer. First, in order to more realistically represent the fate of tritium in a plant exposed to acute variations in ${ }^{3} \mathrm{H}$ releases and meteorology, the TOCATTA- $\chi$ model previously developed to simulate ${ }^{14} \mathrm{C}$ transfers to pasture on an hourly timestep basis $[3,4]$ should be adapted to take account for processes specific to tritium, for example by integrating the water cycling within vegetation. Second, future experimental networks should cover all media (air, soil, rain, plant) and consider all forms of tritium and possible conversion reactions between these forms over time, along with controlled or at least constrained environmental conditions [2]. To achieve this (ambitious) goal, IRSN is setting up an in-situ laboratory on a ryegrass field plot closed to the AREVA reprocessing plant of La Hague, from 2013 to 2017, as was done in the past for the assessment of transfer of radiocarbon in grass [1]. More specifically, the main objective of this large-scale project is to better understand and evaluate transfer processes of tritium in several forms (HT, HTO) from the atmosphere (air and rainwater) to grass and soil. The hourly timestep model development is quite ambitious in that some of the required inputs are not sampled hourly. However, efforts are made to carry out high-frequency samples, such as ${ }^{85} \mathrm{Kr}$ measurements recorded every minute, from which it is possible to reconstruct atmospheric input data at an hourly time-step.

The goals of this paper are (1) to present the organization of the experimental design of the study dedicated to transfers of tritium in a grassland ecosystem, (2) to document the major assumptions, conceptual modelling and mathematical formulations of tritium transfers in soil-plant systems that have been implemented in the SYMBIOSE-3H model [4], and (3) to present the method used to reconstruct the atmospheric concentrations of HT and HTO on an hourly basis.

\section{The IRSN experimental design}

Because of the releases of ${ }^{3} \mathrm{H}$ in the atmosphere associated with normal operation of the AREVA NC La Hague nuclear reprocessing plant, the specific activity of ${ }^{3} \mathrm{H}$ observed in various environmental matrices located a few kilometers away from the discharge point is on average ten times higher than the natural background level. In addition, various studies have demonstrated the existence of persistent uncertainties on the transfer of tritium from atmospheric emissary to terrestrial ecosystem [5] such as grasslands - first essential links of a typical food chain of man. In this context, the experimental field set up by the IRSN $2 \mathrm{~km}$ downwind from the nuclear fuel recycling plant of La Hague (AREVA NC) has 
been monitoring since June 2013 tritium concentration and transfer fluxes in/between environmental samples (air, rain, grass, soil) of a grassland ecosystem, together with meteorological parameters acquisition. The objectives of this experimental field are:

(i) to better understand the organically-bound-tritium (OBT) formation in plant by photosynthesis;

(ii) to evaluate transfer processes of tritium in several forms (HT, HTO) from the atmosphere (air and rainwater) to grass and soil;

(iii) to develop a model allowing to reproduce the dynamic response of the ecosystem to tritium atmospheric releases depending of variable environmental conditions.

So far, specific instrumentation and tests have been performed successfully in the laboratory and instrumentations (e.g. lysimeters) have been installed on the technical platform of the in situ laboratory. Since summer 2013, tritium activity measurements have been carried out in grass (monthly measurements of HTO, OBT), in air, rainwater, soil (daily measurements of HT, HTO) according to a specific sampling plan (see table 1). $\mathrm{CO}_{2}, \mathrm{H}_{2} \mathrm{O}$ fluxes between soil and air compartments are being measured as well.

Table 1: Sampling plan for the years 2013-2015.

\begin{tabular}{|l|c|c|c|c|c|}
\hline \multirow{2}{*}{ Sample } & \multirow{2}{*}{ Location } & Frequency & \multicolumn{4}{|c|}{ Analysis } \\
\cline { 4 - 6 } & & (days) & HTO & HT & OBT \\
\hline Air & In situ lab & 30 & $\mathrm{x}$ & $\mathrm{x}$ & \\
\hline Air & In situ lab & 2 & $\mathrm{x}$ & & \\
\hline Rain water & In situ lab & 2 & $\mathrm{x}$ & & \\
\hline Plant & Permanent grass & 15 & $\mathrm{x}$ & & $\mathrm{x}$ \\
\hline Soil $(0-20 \mathrm{~cm})$ & Permanent grass & 30 & $\mathrm{x}$ & & $\mathrm{x}$ \\
\hline Soil water & Permanent grass & 2 & $\mathrm{x}$ & & \\
\hline Plant & Lysimeters & 15 & $\mathrm{x}$ & & $\mathrm{x}$ \\
\hline Soil $(0-20 \mathrm{~cm})$ & Lysimeters & 30 & $\mathrm{x}$ & & $\mathrm{x}$ \\
\hline Soil water & Lysimeters & 30 & $\mathrm{x}$ & & \\
\hline
\end{tabular}

\section{Modelling approach}

\subsection{Model main assumptions and characteristics}

TOCATTA- $\chi$ is a dynamic compartment model developed at IRSN for managed (or unmanaged) productive pastures. The model is being implemented in the SYMBIOSE modelling platform to simulate ${ }^{3} \mathrm{H}$ (and ${ }^{14} \mathrm{C}$ ) transfer in grassland ecosystems exposed to atmospheric ${ }^{3} \mathrm{H}$ (and ${ }^{14} \mathrm{C}$ ) emissions from nuclear facilities operating under normal or accident conditions. The model was previously developed and tested on an hourly time-step basis for ${ }^{14} \mathrm{C}$ transfer to pasture $[3,4]$ and is under development for tritium to take into account acute variations in ${ }^{3} \mathrm{H}$ releases and meteorology. It has the following main characteristics and assumptions:

- The model is based on an hourly time-step; 
- It is driven by monthly (and every two-days) atmospheric concentrations of tritiated water vapour (HTO) above the canopy and hourly weather input data for radiation, temperature, relative humidity, wind speed, and precipitation;

- The model integrates the day / night cycle of plant physiological behavior (photosynthetic uptake, respiratory loss, water and nutrient status, plant aboveground and below-ground dry matter production) derived from a simplified version of the PASIM (Pasture SImulation Model) process-based pasture model [6];

- The net photosynthetic production of OBT in plant parts is linked to the tissue free water tritium (TFWT) concentration in leaves, ignoring the OBT production during the night time [7]. It is a function of leaf $\mathrm{CO}_{2}$ assimilation rate (net of respiration) derived from the biochemical Farquhar model [8] while the leaf area index (LAI) and the radiation scheme have been estimated in a quite simple manner [4];

- A physiological approach is used to integrate LAI and resistances in the calculations of exchange velocities at the leaf/air and soil/air interfaces;

- The model uses the same conceptual and mathematical modelling approaches as defined in SYMBIOSE [1]: the conceptual framework is based on the interaction matrix formalism (cf. section II.B), while the mathematical model is implemented as a series of first-order differential equations, defined for time-varying release conditions and expressing conservation of radionuclide activity for each compartment of the conceptual model. The time rate of change of the activity or concentration in a given compartment is mostly expressed by summing the different mass transfer fluxes coming in/out from/to other interacting compartments.

\subsection{Conceptual model}

The plant conceptual model in TOCATTA- $\chi$ comprises three compartments (table 2): (i) the substrate pool (i.e. sap), (ii) the shoot structural dry matter and (iii) the root structural dry matter. Other simplifications were made [3, 4]. For example, first neither the age nor the development stage of the plant are considered. Second, it is assumed only one layer inside the canopy. This affects both the radiation scheme and the photosynthesis computation [4]. Third, only the whole plant above the ground (i.e. the shoot biomass) along with the root have been considered, i.e. the stem, sheath, ear and laminae are not considered separately. Last, the pool of tritium in soil is assumed to be only tritiated water dissolved in soil pore water of the single soil layer. The soil HTO compartment is subject to loss because of root uptake. In addition, the processes of diffusion and migration in the soil are neglected.

\subsection{Model test}

TOCATTA- $\chi$ was previously tested against in situ data of ${ }^{3} \mathrm{H}$ activities measured in 2011 on the grass field plot located in the vicinity of the AREVA NC La Hague reprocessing plant [9]. However the model did not reproduce adequately the 
observed month-to-month variability; in particular, it overestimated OBT activity during the summer months. To cope with that matter, some processes have been identified to be further improved. Above all, an essential prerequisite for improving the model-measurements comparison is the reconstruction on a fine time scale (i.e. hourly) of dynamics of tritium concentrations in the atmosphere.

\section{Reconstruction of atmospheric concentrations of tritium at an hourly time-step}

\subsection{Need to restore hourly dynamics in air and rain}

As mentioned above, a good estimation of the atmospheric tritium concentrations to sufficiently high frequency levels (e.g. hourly) is an essential condition for ensuring the quality of model evaluation. Indeed hourly HTO concentration in air is required as input to the TOCATTA- $\chi$ model (atmospheric HT concentrations will also be required in the future). In addition exchange kinetics between the vapor in the atmosphere tritiated water (HTO) and tissue-free-water-tritium of the plant (TFWT) are very fast, of about half an hour (Belot et al. [10]). However the measurement results obtained for the atmospheric compartment, provided with a period of 2 days, do not allow accounting for the rapid changes in atmospheric concentrations and hence rapid exchange kinetics between HTO in air and TFWT. In addition, there is no direct way to sample atmospheric HTO on an hourly time basis.

Regarding tritiated hydrogen (HT), the environmental measurements are carried out at intervals of one month; it is possible to reconstruct hourly dynamics using Krypton-85 $\left({ }^{85} \mathrm{Kr}\right)$. Indeed, HT and ${ }^{85} \mathrm{Kr}$ are emitted into the atmosphere concomitantly and only by the two main chimneys UP2-800 and UP3. Since ${ }^{85} \mathrm{Kr}$ is a plume tracer, it could be measured at very high resolution $(\sim 1$-minute sampling). The ${ }^{85} \mathrm{Kr}$ data were then used to downscale the monthly HT data to hourly time-step relying on a quantitative relationship between ${ }^{85} \mathrm{Kr}$ and HT release rates (see eqn. (1)), as was done in the past for long-term ${ }^{14} \mathrm{C}$ data. Consequently based on ${ }^{85} \mathrm{Kr}$ measurements every minute at $1.5-\mathrm{m}$ above the plot and the actual ${ }^{85} \mathrm{Kr}$ and $\mathrm{HT}$ monthly discharge rates from the AREVA NC reprocessing plant, the atmospheric HT activity above the plot was estimated on an hourly basis from June 2013 to June 2014. Thus, instead of using an atmospheric dispersion model as input to TOCATTA- $\chi$, we directly used the hourly activity of HT in air recorded at $1.5-\mathrm{m}$ above the plot.

Unlike HT, tritiated water vapor (HTO) is emitted in the atmosphere not only by the two main chimneys (UP2-800 and UP3) but also by the emissaries of buildings D', STE2 and STE3 (fig. 1).

To reconstruct HTO concentration in air water vapor and rainwater on an hourly basis, it is thus necessary to take into account all sources using ${ }^{85} \mathrm{Kr}$ but also wind direction to take into account the possible influence of buildings D', STE2 and STE3. 
28 Ecosystems and Sustainable Development X

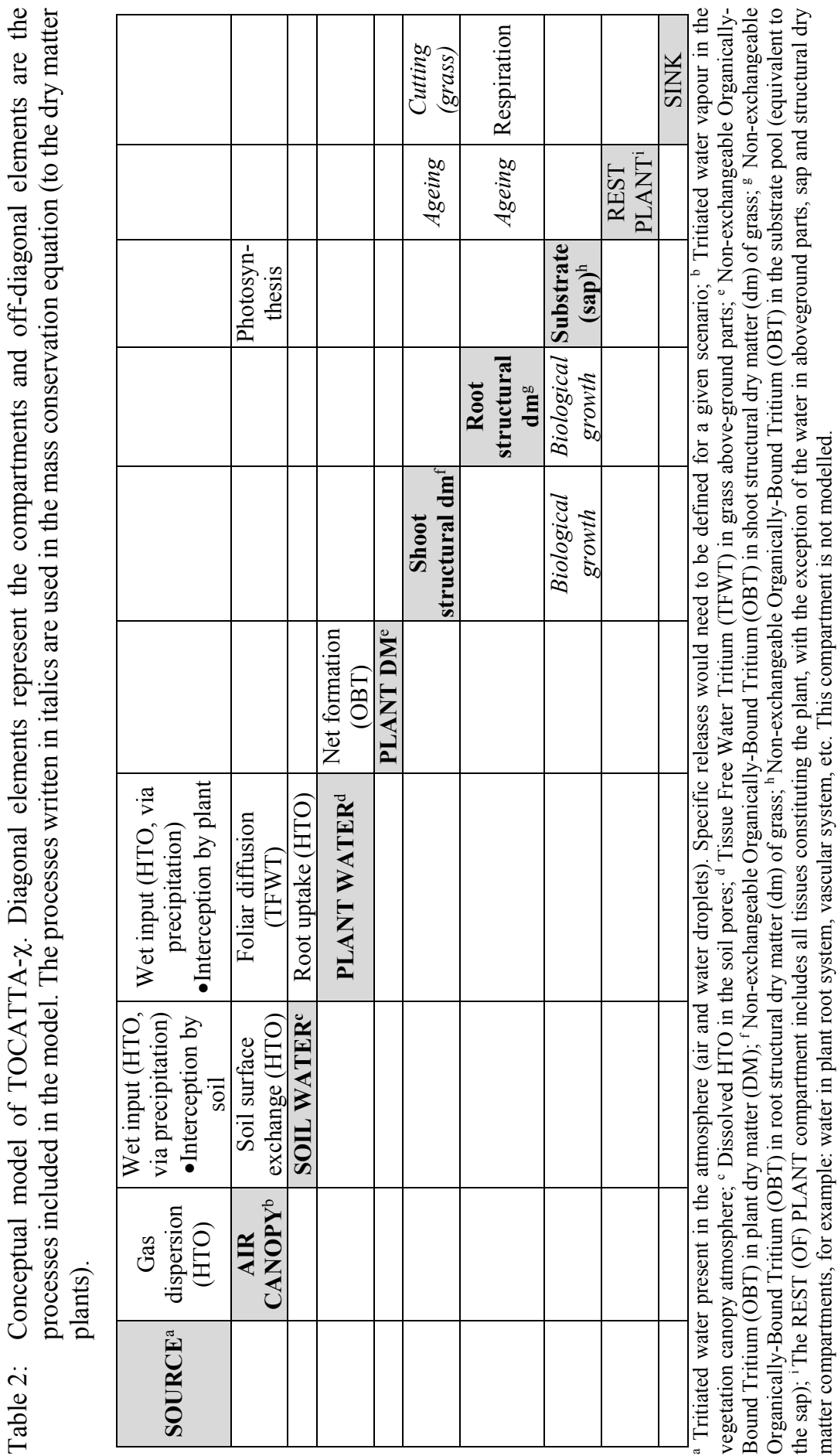




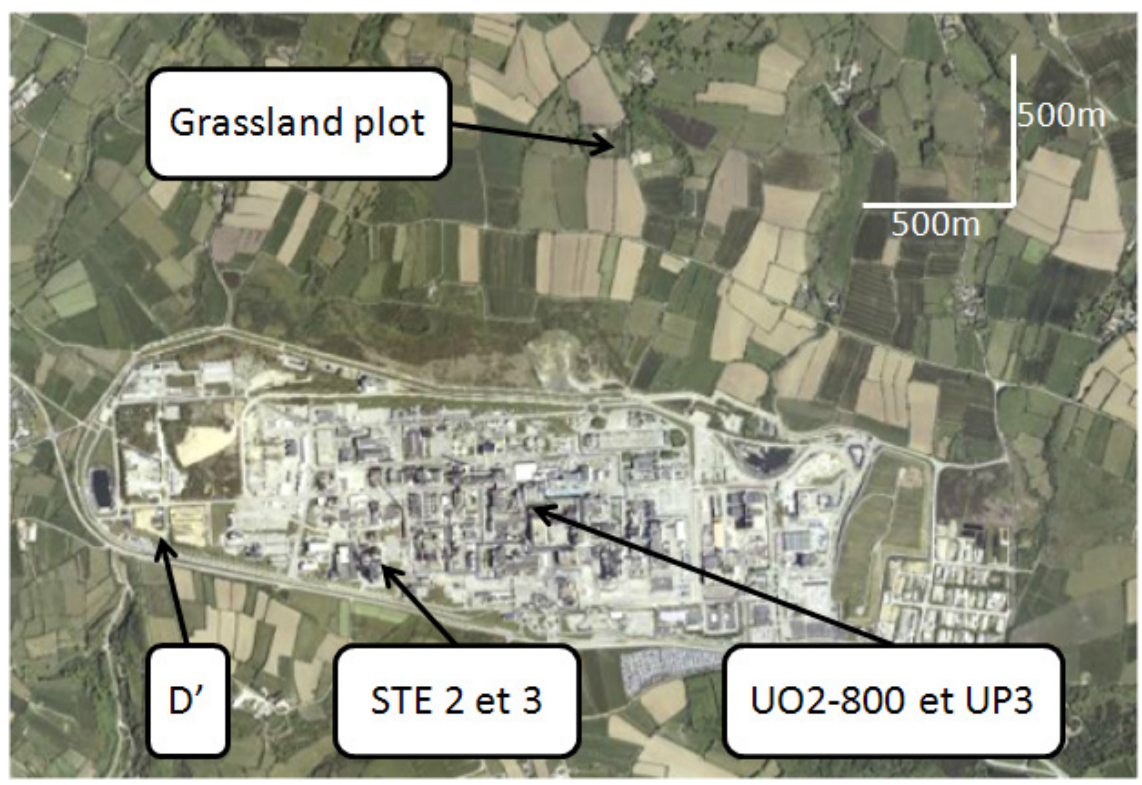

Figure 1: Position of tritium release points.

\subsection{Reconstruction of HT concentration in air at an hourly time-step}

HT and ${ }^{85} \mathrm{Kr}$ are released concomitantly from the same chimneys (UP2-800 and UP3), so the monthly concentration of HT measured in atmosphere is downscaled to hourly time-step according to the following equation:

$$
C_{c}(H T) h_{t}=C_{m}(K r) h_{t} \frac{C_{m}(H T)_{m}}{C_{m}(K r)_{m}}
$$

where $C_{c}(H T) h_{t}, C_{m}(H T) h_{t}$ are hourly air concentrations of HT and ${ }^{85} \mathrm{Kr}$, respectively, calculated at an hourly time-step $\left(\mathrm{Bq} \cdot \mathrm{m}^{-3}\right) ; C_{c}(H T) m, C_{m}(H T) m$ are monthly measured concentrations of HT and ${ }^{85} \mathrm{Kr}$ in air (Bq. $\left.\mathrm{m}^{-3}\right)$.

\subsection{Reconstruction of HTO concentration in air at an hourly time-step}

HTO is partly released from the chimneys UP2-800 and UP3 and partly from the chimneys of the building D', STE2 and STE3; so two equations are used for reconstructing HTO through time.

\subsection{Calculation of hourly concentrations above the plot coming from the chimneys UP2-800 and UP3}

$$
C_{c}\left(H T O_{U P}\right) h_{t}=C_{c}(H T) h_{t} \frac{R\left(H T O_{U P}\right)_{m}}{R(H T)_{m}}
$$

where $C_{c}\left(H T O_{U P}\right) h_{t}$ and $C_{c}(H T) h_{t}$ are hourly concentrations of HTO and HT (see eqn. (1)) in air calculated at time $\mathrm{t}$ and coming from the chimneys UP2-800 and UP3 $\left(\mathrm{Bq} . \mathrm{m}^{-3}\right) ; R\left(H T O_{U P}\right) m$ is the monthly release of HTO in air coming from the chimneys UP2-800 and UP3 (Bq); $R(H T) m$ monthly release of HT (Bq). 


\subsubsection{Calculation of hourly concentrations above the plot coming from the chimneys D ', STE2 and STE3 (in the same angular sector, given a beating wind of $20^{\circ}$ )}

In most cases, $\mathrm{C}_{\mathrm{c}}\left(\mathrm{HTO}_{\mathrm{UP}}\right) 48 \mathrm{~h}<\mathrm{C}_{\mathrm{c}}\left(\mathrm{HTO}_{\mathrm{UP}}\right) 48 \mathrm{~h}$, so we have the following equations:

$$
\begin{gathered}
C_{c}\left(H T O_{A C}\right) 48 h=C_{m}(H T O) 48 h-C_{c}\left(H T O_{U P}\right) 48 h \\
C_{c}\left(H T O_{A C}\right) h_{t}=C_{c}\left(H T O_{A C}\right) 48 h \frac{f c_{t}}{\sum_{1}^{48} f c_{t}} 48
\end{gathered}
$$

where: $\mathrm{C}_{\mathrm{c}}\left(\mathrm{HTO}_{\mathrm{AC}}\right) \mathrm{h}_{\mathrm{t}}$ is the averaged concentration of HTO in air calculated over 48 hours, coming from the chimneys D', STE2 and STE3 (Bq.m ${ }^{-3}$ ); $\mathrm{C}_{\mathrm{c}}\left(\mathrm{HTO}_{\mathrm{AC}}\right) 48 \mathrm{~h}$ is the hourly concentration of $\mathrm{HTO}$ in air calculated at time $\mathrm{t}$ and coming from the chimneys D', STE2 and STE3 $\left(\mathrm{Bq} \cdot \mathrm{m}^{-3}\right) ; \mathrm{fc}_{\mathrm{t}}$ is the weighing factor of atmospheric HTO concentration calculated at time $t$ equal to discrete values ( 0 or 1$)$ depending on wind direction ( 1 if wind direction is between $185^{\circ}$ and $241^{\circ} ; 0$ in other cases)

In the future, this weighting factor could be calculated with the laws of Gauss.

\subsubsection{Calculation of total hourly concentration of HTO in air}

The total concentration of atmospheric HTO at an hourly time-step is the sum of two sources of atmospheric tritium, i.e. that from the chimney UP2-800 and UP3 (see eqn. (2)) and that from the other three chimneys (eqn. (4)):

$$
C_{c}(H T O) h_{t}=C_{c}\left(H T O_{U P}\right) h_{t}+C_{c}\left(H T O_{A C}\right) h_{t}
$$

The hourly reconstructed dynamics of HT and HTO concentrations in the atmosphere are presented fig. 2 .

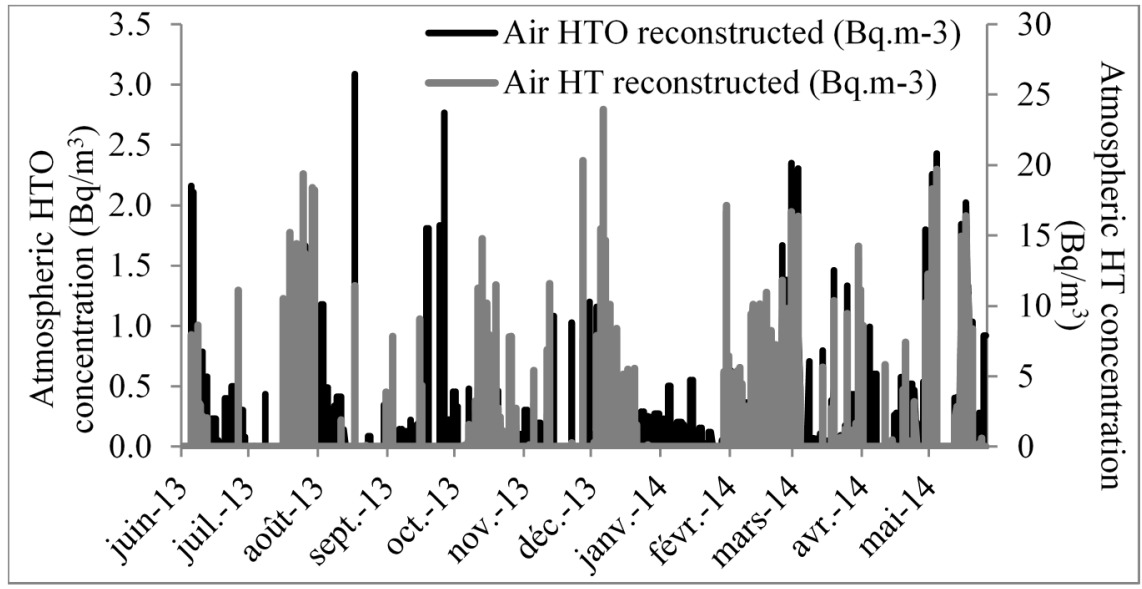

Figure 2: Atmospheric concentrations of HT (right axis) as estimated by the Krypton-85 methodology and atmospheric concentrations of HTO (left axis) as estimated from HT concentration and methodology explained in the text. 


\subsection{Reconstruction of HTO concentration in rainwater with an hourly time-step}

Hourly concentration of HTO in rainwater depends on the concentration of HTO in air and intensity of precipitation. The calculation takes into account these two parameters in the calculation of the weighing factor.

$$
C_{c}\left(H T O_{P L}\right) h_{t}=C_{m}\left(H T O_{P L}\right) 48 h \frac{f p_{t}}{\sum_{1}^{48} f p_{t}} \frac{\sum_{1}^{n} I P_{t}}{I P_{t}}
$$

where: $C_{c}\left(H T O_{P L}\right) h_{t}$ is the hourly concentration of HTO in rainwater calculated at time $\mathrm{t}(\mathrm{Bq} . \mathrm{L}-1) ; C_{m}\left(H T O_{P L}\right) 48 \mathrm{~h}$ is the averaged concentration of HTO in rainwater measured over 48 hours $\left(\mathrm{Bq} . \mathrm{L}^{-1}\right)$; $f p_{t}$ : Weighing factor of HTO concentration in rainwater at time $t$, i.e. the product of the concentration of HTO in air (Bq.m-3) and intensity of precipitation $\left(\mathrm{mm} \cdot \mathrm{hr}^{-1}\right) ; I P_{t}$ : Intensity of precipitations $\left(\mathrm{mm} \cdot \mathrm{h}^{-1}\right)$ for a given number $\mathrm{n}$ of precipitation.

\section{Conclusion and perspectives}

In the present study, gaseous releases of tritium from the AREVA NC nuclear reprocessing plant in normal operation can be intense and intermittent over a period of less than 24 hours. The TOCATTA- $\chi$ model previously developed to simulate ${ }^{14} \mathrm{C}$ transfers to pasture on an hourly time-step basis [2, 3] has been adapted to take account for processes specific to tritium. Previous modelmeasurements comparison studies $[2,9]$ had shown that TOCATTA- $\chi$ could be improved in terms of kinetics of tritium transfer and further tested against the extensive set of field measurements that has been obtained since 2013. In order to address the great number of factors that affect transfer processes of tritium (e.g. air and soil humidity, temperature, current and recent rainfall, season, growth stage etc.), the IRSN project is also carrying out high frequency (daily) sampling in air, rainwater and soil to reduce uncertainties in tritium transfer coefficients. Secondly, the results of this experiment will allow improving the TOCATTA- $\chi$ model accordingly.

As a prerequisite for performing further simulation runs and improving model evaluation, this article emphasizes the need to properly reconstruct hourly dynamics of HT and HTO atmospheric concentrations.

\section{References}

[1] Le Dizès, S., Maro, D., Hebert, D., Gonze, M.-A. \& Aulagnier, C., TOCATTA: A dynamic transfer model of ${ }^{14} \mathrm{C}$ from the atmosphere to soilplant systems. J. Environ. Radioact., 105, pp. 48-59, 2012.

[2] Le Dizès, S., Aulagnier, C., Henner, P. \& Simon-Cornu, M., TOCATTA: a dynamic transfer model of ${ }^{3} \mathrm{H}$ from the atmosphere to soil-plant systems. $J$. Environ. Radioact., 124, pp. 191-204, 2013.

[3] Aulagnier, C., Le Dizès, S., Maro, D., Hebert, D., Lardy, R., Martin, R. \& Gonze, M.-A., Modelling chronic and accidental releases of carbon-14 to 
the environment: A case study in a grass field near AREVA-NC La Hague. J. Environ. Radioact., 112, pp. 52-59, 2012.

[4] Aulagnier, C., Le Dizès, S., Maro, D., Hebert, D., Lardy, R. \& Martin, R, The TOCATTA- $\chi$ model for assessing ${ }^{14} \mathrm{C}$ transfers to grass: an evaluation for atmospheric operational releases from nuclear facilities. J. Environ. Radioact., 120, pp. 81-93, 2013.

[5] AIEA. Transfer of Tritium in the Environment after Accidental Releases from Nuclear Facilities. Report of Working Group 7. Tritium Accidents of Emras II Topical Heading. Approaches for Assessing Emergency Situations. Environmental Modelling for Radiation Safety (Emras II) Programme, TEC-DOC-1738, IAEA, Vienne, 2014.

[6] Riedo, M., Grub, A., Rosset, M., \& Fuhrer, J., A pasture simulation model for dry matter production, and fluxes of carbon, nitrogen, water and energy. Ecological Modelling, 105, pp. 141-183, 1998.

[7] Melintescu, A. \& Galeriu, D., Exchange velocity approach and the role of photosynthesis for tritium transfer from atmosphere to plants. Fusion Sci. Technol., 60, pp. 1179-1182, 2011.

[8] Farquhar, G.D. \& von Caemmerer, S., Modeling of photosynthetic responses to environmental conditions. Physiological Plant Ecology II, eds. O.L. Lange, P.S. Nobel, C.B. Osmond, H. Ziegler, Springer Verlag: Heidelberg, pp. 549-587, 1982.

[9] Le Dizès S., Maro, D., Rozet, M., Thomas, L., Hébert, D., Solier, L., Voiseux, C., Defenouillère, P., Morillon, M. \& Connan, O. Modeling and validating tritium transfer in a grassland ecosystem in response to ${ }^{3} \mathrm{H}$ releases. Tritium conference, Nice, Oct. 21-25, 2013.

[10] Belot, Y., Roy, M. \& Métivier, H., Le TRITIUM de l'environnement à l'Homme, Editions de Physique: Paris, 1996. 